Suwasono, $B^{*}$

Putra, IKAS

Kristiyono, TA

Azhar, A

http://dx.doi.org/10.21278/brod72202

\title{
ADHESIVE COATING VALUE BASED ON THE MAIN INGREDIENT OF SHIP PAINT
}

\author{
UDC 620.197.6:621.78.019.84:539.61 \\ Professional paper
}

\begin{abstract}
Summary
Coatings are important instruments in inhibiting the corrosion rate. Field facts in various Indonesian shipping industries show that the choice of organic materials as coating for ship paint uses epoxy, vinyl and polyurethane. Therefore an experimental study is needed on the adhesion ability of paint as a coating for ship armor with these three types of organic materials. The preparation of steel specimens with type ASTM A36 is carried out by blasting, visual inspection standard ISO 8501-1, and roughness test standard ISO 8503-4. Painting of specimens by measuring the thickness of the paint in the wet conditions ASTM D4414 standard and ASTM D4138 standard dry conditions. Treatment of specimens in two conditions, are: tropichal weather condition and salt spray conditon. Observation of specimens by scanning electron microscope and adhesion test standard ASTM D4541-02. The final result shows that the best adhesion ability of the main paint coating in tropical weather conditions was a polyurethane coating with no blister characteristics, but there are fractures on the surface of the material. While the main material for the best coating in salt spray conditions was epoxy coating with characteristics that are resistant to blisters and blends with the surface of the material.
\end{abstract}

Key words: epoxy; vinyl; polyurethane; adhesive

\section{Introduction}

Coating on steel ship buildings is an important thing to do in an effort to inhibit the rate of corrosion. Corrosion on ships can cause safety, technical and economic problems. According to Roberge [1], the importance of studying corrosion is to save costs and minimize losses due to material reduction. Direct losses on costs incurred for overlaying corroded parts, replacing corroded parts, and workers' wages. Indirect losses include discontinuation of operations, products that are affected by corroded components, loss of efficiency, product contamination, over-design due to the addition of corroded components. S.B. Lyon et al. [2], paint coatings are generally regarded as functioning by providing a barrier between the substrate and the environment, ideally providing a high resistance to ionic movement. 
According to the Mayne [3], the movement of ions in organic coatings is slow and rate limiting. The charge may be carried by cations or anions (or both) depending upon the nature of the polymer. Consider a clean, rust-free steel sheet coated with $25 \mu \mathrm{m}$ of clear lacquer such as plasticized polystyrene (Figure 1a). After a few weeks of exposure to the environment, a red-brown deposit is observed on the surface of the lacquer, and blisters containing a clear liquid may be observed underneath the lacquer (Figure 1b). Charge transfer must have taken place in order for electrochemical reactions to proceed. Charge transfer is ionic in the electrolyte and electronic in the substrate, so how is the charge carried in the polymer (Figure 1c). The appearance of the red-brown deposit on the surface suggests $\mathrm{Fe}^{2+}$ ions must migrate from the substrate into the polymer (Figure 1d). The growth of the under-film blister suggests oxygen and water must migrate from the electrolyte into the polymer (Figure 1). Of course, where anodes and cathodes exist together within a single interfaci al defect, ionic transport through the coating thickness would no longer control the under film corrosion process in the manner shown here.
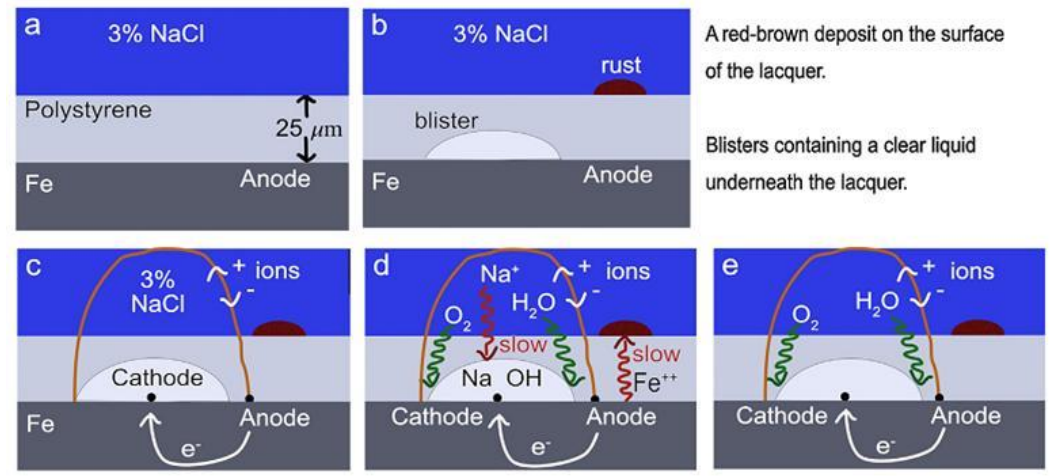

Fig. 1 Experimental observation of under-film corrosion: (a) coating applied on clean substrate, (b) after a few weeks exposure to electrolyte, (c) charge transfeer between electrolyte and substrate, (d) ions migrate from substrate, (e) oxygen and water migrate

Therefore the type of coating that is commonly used is a type of liquid coating (resin) which includes epoxy, vinyl, and polyurethane. The epoxy resin has characteristics of resistance to chemical reactions and impact, low shrinkage value, and good adhesive properties to various materials (Claver) [4]. The vinyl resin has the characteristics of resistance to liquid solvents and various solvents others (Zaske \& Goodman) [5]. The polyurethane resin has characteristics of resistance to weather, solvents, and mechanical damage (Dodiouk \& Goodman) [6].

On the other hand, research by Yong Li et al. [7] on epoxy composites with zinc rich primer and silver epoxy enamel sprayed on Q235 steel, where this type of steel is commonly used for bridges, vehicles, containers and ships. Samples were exposed to an atmospheric environment for 18 months and immersed in $5 \% \mathrm{NaCl}$ solution for 250 days. The final results show that the resistance of painting is better in an atmospheric environment, where the atmospheric resistance coefficient is higher than the resistance coefficient in the $5 \% \mathrm{NaCl}$ solution immersion. Meanwhile, research by R. Vera et al. [8] on painting with a polyurethane coating that is sprayed on A36 steel which is commonly used for industrial structures in marine environments. Samples were exposed to an atmospheric environment at five different locations for 24 months and a salt spray test with a maximum exposure of 3,000 hours. The final results show that after 2 years of exposure or after 3,000 hours in the salt spray chamber, both paints still show evenly protective properties.

Based on the above conditions, the researchers carried out experimental activities to explore and compare the value of the adhesiveness of paint as a coating for ship steel with three types of organic materials including: epoxy, vinyl, and polyurethane. 


\section{Experimental}

\subsection{The test specimen}

The test specimen was cut from a steel plate that conforms to ASTM A36 standards with a specimen size of $100 \times 50 \times 10 \mathrm{~mm}$. The blasting process uses the dry abrasive cleaning method, Steel Grit 15 type of abrasive material, and according to ASTM D4417 standards as shown in Figures 2 and 3.

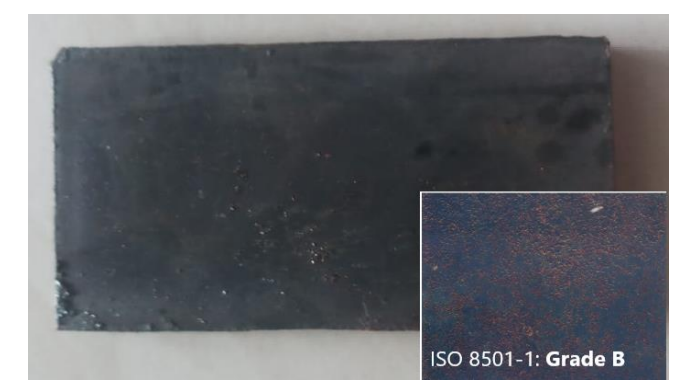

Fig. 2 Steel plate specimen: $100 \times 50 \times 10 \mathrm{~mm}$

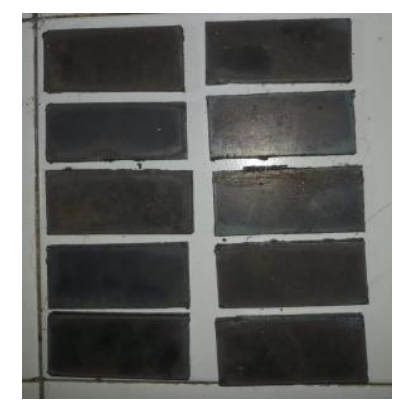

(a)

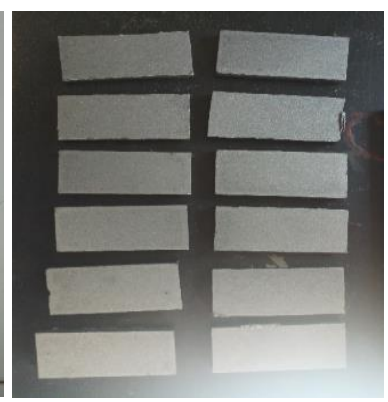

(b)

Fig. 3 Specimen condition: (a) Before blasting and (b) After blasting

\subsection{Visual inspection of blasted samples}

Visual inspection of blasted surface was carried out to see the results of the blasting process on the specimen by comparing the cleanliness level of the specimen with the image contained in the ISO 8501-1 standard, it was Sa $2 \frac{1}{2}$ as shown in Figure 4.

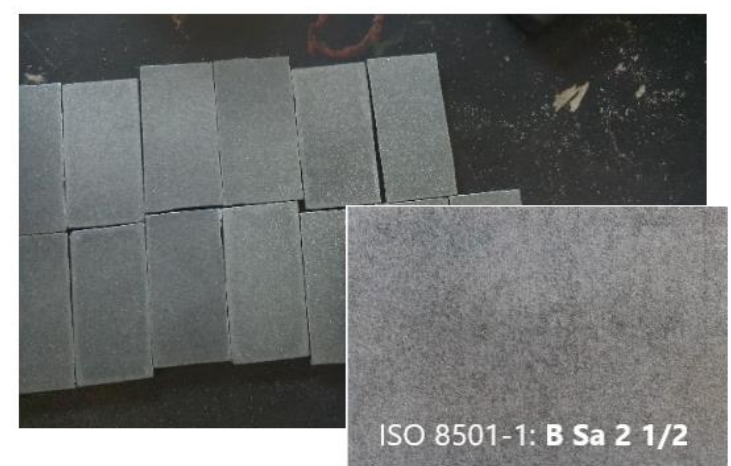

Fig. 4 Visual inspection of blasted surface; grade Sa $2 \frac{1}{2}$ according to ISO 8501-1

\subsection{Roughness test}

A roughness test was carried out to ensure that the surface roughness of the specimen was in accordance with ISO 8503-4 and NORSOK M-CR-501 standards. In this study using Testex Replica Tape and Elcometer facilities with roughness values at the Sa-3 cleanliness level reaching $50 \mu \mathrm{m}-75 \mu \mathrm{m}$ (A. M. Berendsen) [9] as shown in Figure 5. 


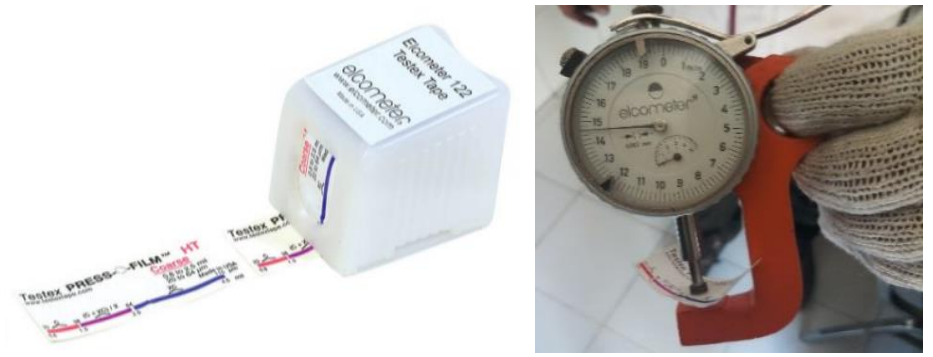

Fig. 5 Roughness meaurement with Elcometer Testex Replica and Elcometer 124

The Elcometer 122 Testex Replica Tape was a very simple technique to measure a surface profile. The foam side of the Testex Tape was used to mould the peak-to-valley profile of the surface and then the measurement was taken by the Elcometer 124, a mechanical Surface Profile and Thickness Gauge.

\subsection{Coating}

The comparison between main paint ingredients (part A) and hardener (part B) following the rules of paint product in general and the specimen coating using one layer. The comparison for epoxy paint $2: 1$, for vinyl paint, and for polyurethane paint $4: 1$. The coating process in this specimen was done horizontally.

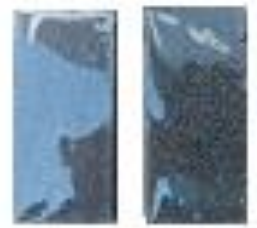

(a)

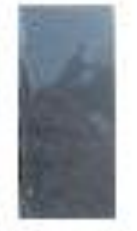

ig. 6 Specimens coating with resin (a)
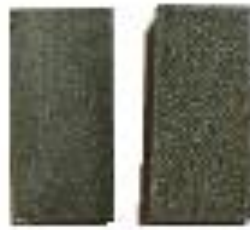

(b)

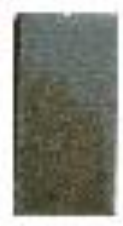

Epox
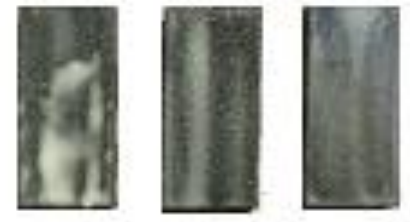

(c)

Measurement of paint thickness in wet conditions using the wet film thickness (WFT) comb and the implementation method according to ASTM D4414 standard with a wet thickness between 200-300 $\mu \mathrm{m}$ as shown in Figure 7 (a).

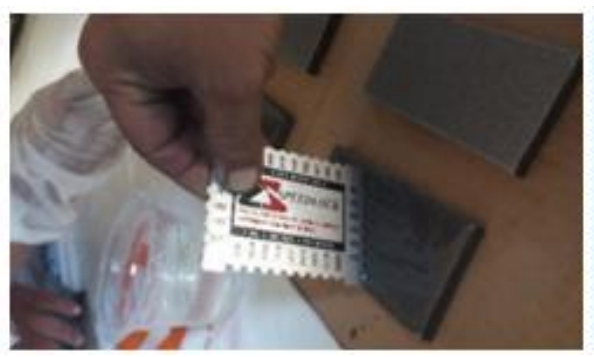

(a) WFT comb

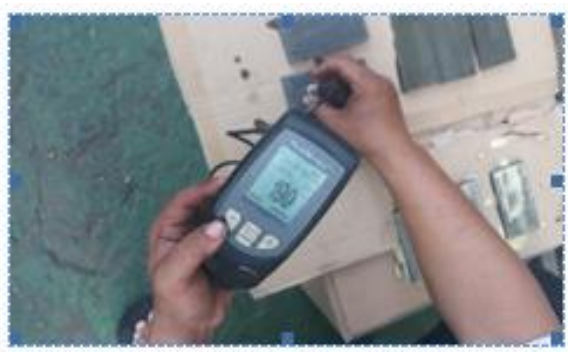

(b) DFT comb

Fig. 7 Measurement of paint thickness

Dry film thickness (DFT) comb and the implementation method according to the ASTM D4138 standard with a wet thickness between $150-200 \mu \mathrm{m}$ as shown in Figure 7 (b). Meanwhile, the determination of solid by volume in experiment refers to paint products that use the same base material.

\subsection{Tropical weather test}

A tropical weather test was carried out to analyse the resistance of materials and coatings in open spaces (sunlight, humidity, and temperature). The specimens were placed on a support with a angle of $90^{\circ}$ and exposed to the weather for 576 hours, where every 192 hours a check was made for changes in the coating material as shown in Figure 8. 

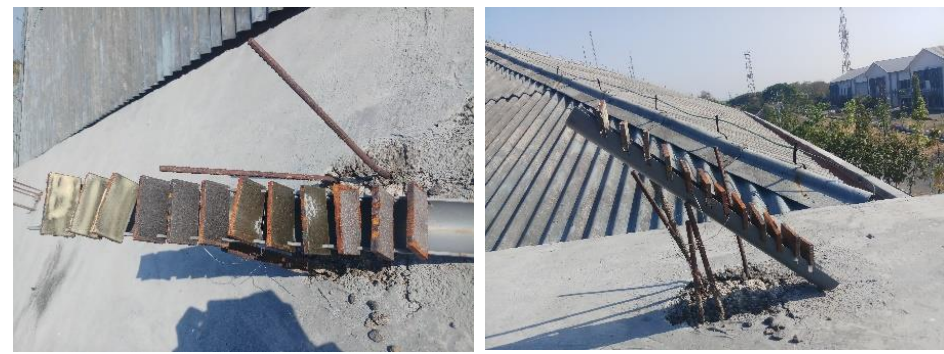

Fig. 8 Trophical weather test

Testing with atmosphere exposure was carried out at the laboratory of chemical and material from Indonesian Navy.

\subsection{Salt spray test}

The salt spray test chamber was a test chamber that assesses the ability of material and its protective layer to withstand salt spray corrosion. Salt spray chambers meet international standards, such as ASTM B 117. The composition of the mixture includes: 100 liters of water [H2O], 50 grams of salt $[\mathrm{NaCl}], 350$ grams of ammonium sulphate $\left[\left(\mathrm{NH}_{4}\right)_{2} \mathrm{SO}_{4}\right]$, and 25 millilitres acetic acid glacial $\left[\mathrm{HC}_{2} \mathrm{H}_{3} \mathrm{O}_{2}\right]$. Specimens were placed in a salt spray chamber with a $90^{\circ}$ angle position and a dew rate of 1.0 to $2.0 \mathrm{l} / \mathrm{h}$, with variations in exposure time for 196 hours, 382 hours, and 575 hours as shown in Figure 9.

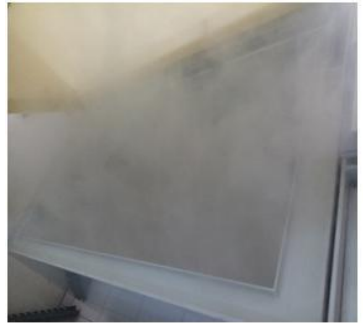

(a) Salt fog phase

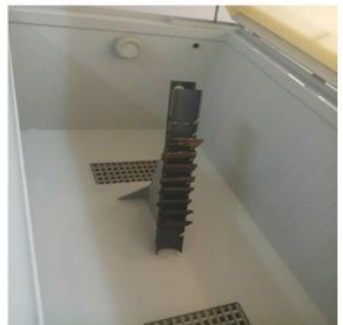

(b) Cold phase

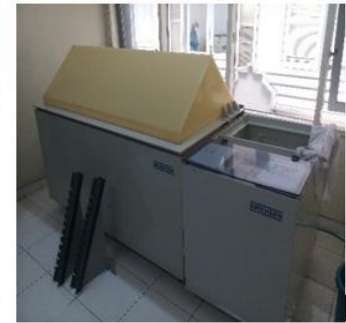

(c) Humidity

Fig. 9 Salt spray test chamber

The operational standard of the ERICHSEN 608 engine - Corrosion Test Apparatus (P-VW 1210 test) has a 4 hour cycle of salt fog phase, 4 hours of cold phase 18 to $28^{\circ}$ Celsius with a humidity of 40 to $60 \%$, and 16 hours of hot phase $40 \pm 3^{\circ}$ Celsius with $100 \%$ humidity.

\subsection{Scanning Electron Microscope}

Scanning Electron Microscope (SEM) was performed to obtain visual information on specimens from topographic surfaces (K. Akhtar et al.) [10] on coating damage and ASTM A36 material as shown in Figure 10.
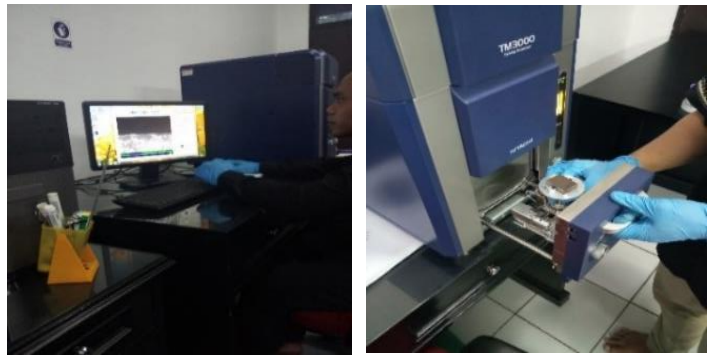

Fig. 10 Scanning Electron Microscope

SEM from the Hitachi Table Top Electron Microscope TM-3000 has 3D image capabilities and magnification of x15 to x30,000. 


\subsection{Adhesive test}

After weather and salt spray treatment the specimens were subjected to adhesion measurement using a Pull-Off Test. The adhesion test was conducted to measure the adhesive strength of a paint layer to the substrate.

The adhesion test was done by attaching 2 dolly pins using epoxy glue for 24 hours before testing. This is done so that the dolly pin can adhere perfectly to the specimen, then the dolly pin is pulled using a dolly cutter to test the adhesive strength of the coating. In the test using Dolly Pull-Off, it can be seen the characteristics of the coating based on the adhesive, cohesive, and tensile strength. The adhesive and cohesiveness values were compared with the ASTM D4541-02 and NORSOK M-CR-501 standards. According to the NORSOK M-CR501 standard for material preparation and painting in shipbuilding the minimum requirement for the adhesive strength of a layer is $5 \mathrm{MPa}$.

\subsection{Scatter plot and trendlines}

Scatter plots use points that represent values for two different numerical variables and were used to observe relationships between variables. The position of each point on the horizontal and vertical axis shows values for individual data points (Mike Yi) [11], (M. Friendly and D. Denis) [12], (D.A. Keim et al.) [13]. Meanwhile, trend lines were created by connecting between peaks or valleys along the trend. There were three types of trend lines: internal, external, and curved. Reliable trend lines through time, points on trend lines, and slope angles of 24 degrees to 30 degrees (W. Selzer) [14], (M. David) [15].

For scatter plot and trend line analysis in this study using Ms. Excel Software to produce 5 (five) types of functions (linear, exponential, logarithmic, polynomial, and power). The value of R-square was getting closer to the value of 1 , then the regression model can be approved (J.W. Gooch) [16].

\section{Results and Discussion}

\subsection{Specimen}

\subsubsection{Roughness level}

The specimen roughness has a minimum roughness value of $70 \mu \mathrm{m}$ and a maximum of $95 \mu \mathrm{m}$ as shown in Table 1 .

Table 1 Roughness test results

\begin{tabular}{|c|l|c|c|c|c|c|c|c|c|}
\hline Material & Material & \multicolumn{7}{|c|}{ Surface roughness value $(\mu \mathrm{m})$} & \multirow{2}{*}{ Average } \\
\cline { 3 - 11 } Coating & Abrasive & 1 & 2 & 3 & 4 & 5 & 6 & 7 & \\
\hline Epoxy & Steel Grit & 70 & 77 & 82 & 74 & 90 & 88 & 87 & 81.14 \\
\hline Vinyl & Steel Grit & 88 & 92 & 71 & 74 & 73 & 84 & 81 & 80.43 \\
\hline Polyurethane & Steel Grit & 95 & 89 & 72 & 75 & 85 & 83 & 76 & 82.14 \\
\hline
\end{tabular}

Table 1 showed that the average roughness value of coating materials for epoxy was $81.14 \mu \mathrm{m}$, vinyl $80.43 \mu \mathrm{m}$, and polyurethane was $82.14 \mu \mathrm{m}$. The three coating materials were included in the medium category in the ISO 8503-1 standard. According to Trijatmiko et al [17] showed that roughness average rating the surface of material was blasted using abrasive material from steel grit type reached of $84.71 \mu \mathrm{m}$. 


\subsubsection{Paint thickness level}

The wet film thickness has a minimum value of $217 \mu \mathrm{m}$ and a maximum of $283 \mu \mathrm{m}$ as shown in Table 2.

Table 2 Wet film thickness testing results

\begin{tabular}{|c|c|c|c|c|c|c|c|}
\hline \multirow{2}{*}{$\begin{array}{c}\text { Material } \\
\text { coating }\end{array}$} & \multirow{2}{*}{ Specimen } & \multicolumn{6}{|c|}{ Wet film thickness test value $(\mu \mathrm{m})$} \\
\hline & & Spot 1 & Spot 2 & Spot 3 & Spot 4 & Spot 5 & Average \\
\hline \multirow{7}{*}{ Epoxy } & 1 & 228 & 222 & 225 & 230 & 227 & 226.40 \\
\hline & 2 & 220 & 222 & 217 & 220 & 219 & 219.60 \\
\hline & 3 & 217 & 225 & 219 & 224 & 218 & 220.60 \\
\hline & 4 & 222 & 217 & 220 & 219 & 217 & $219.00^{*}$ \\
\hline & 5 & 228 & 225 & 226 & 225 & 226 & 226.00 \\
\hline & 6 & 217 & 221 & 220 & 223 & 222 & 220.60 \\
\hline & 7 & 219 & 223 & 223 & 224 & 224 & 222.60 \\
\hline \multirow{7}{*}{ Vinyl } & 1 & 250 & 247 & 244 & 246 & 244 & 246.20 \\
\hline & 2 & 237 & 244 & 245 & 239 & 240 & $241.00^{*}$ \\
\hline & 3 & 244 & 243 & 244 & 245 & 240 & 243.20 \\
\hline & 4 & 236 & 239 & 235 & 235 & 234 & 235.80 \\
\hline & 5 & 246 & 245 & 244 & 249 & 247 & 246.20 \\
\hline & 6 & 239 & 244 & 244 & 242 & 240 & 241.80 \\
\hline & 7 & 239 & 245 & 245 & 240 & 241 & 242.00 \\
\hline \multirow{7}{*}{ Polyurethane } & 1 & 279 & 280 & 276 & 274 & 274 & 276.60 \\
\hline & 2 & 282 & 278 & 276 & 283 & 283 & 280.40 \\
\hline & 3 & 272 & 278 & 275 & 275 & 277 & $275.40^{*}$ \\
\hline & 4 & 277 & 280 & 275 & 276 & 277 & 277.00 \\
\hline & 5 & 278 & 277 & 274 & 279 & 281 & 277.80 \\
\hline & 6 & 273 & 279 & 275 & 275 & 276 & 275.60 \\
\hline & 7 & 277 & 281 & 278 & 275 & 279 & 278.00 \\
\hline
\end{tabular}

Table 2 showed that the average thickness value of paint in wet conditions for epoxy $222.114 \mu \mathrm{m}$, vinyl is $242.314 \mu \mathrm{m}$, and polyurethane $277.257 \mu \mathrm{m}$. The three coating materials were included in the ASTM D4414 standard.

The dry film thickness has a minimum value of $170 \mu \mathrm{m}$ and a maximum of $198 \mu \mathrm{m}$ as shown in Table 3.

Table 3 showed that the average thickness value of paint in dry conditions for epoxy was $181.857 \mu \mathrm{m}$, vinyl $184.029 \mu \mathrm{m}$, and polyurethane $181.40 \mu \mathrm{m}$. The three coating materials were included in the ASTM D4138 standard.

Based on Table 2, Table 3, and the average from three specimens coating (epoxy, vinyl, and polyurethane), so the calculation DFT / WFT ratio difference regarding solids volume was related to uneven spray paint over a nozzle as shown in Table 4, 5, and 6. 
Table 3 Dry film thickness testing results

\begin{tabular}{|c|c|c|c|c|c|c|c|}
\hline \multirow{2}{*}{$\begin{array}{c}\text { Material } \\
\text { coating }\end{array}$} & \multirow{2}{*}{ Specimen } & \multicolumn{6}{|c|}{ Dry film thickness test value $(\mu \mathrm{m})$} \\
\hline & & Spot 1 & Spot 2 & Spot 3 & Spot 4 & Spot 5 & Average \\
\hline \multirow{7}{*}{ Epoxy } & 1 & 181 & 177 & 192 & 188 & 176 & 182.80 \\
\hline & 2 & 179 & 176 & 188 & 190 & 170 & 180.60 \\
\hline & 3 & 182 & 179 & 190 & 185 & 177 & 182.60 \\
\hline & 4 & 177 & 178 & 191 & 186 & 175 & 181.40 \\
\hline & 5 & 177 & 176 & 187 & 187 & 174 & 180.20 \\
\hline & 6 & 182 & 175 & 190 & 188 & 176 & 182.20 \\
\hline & 7 & 181 & 180 & 190 & 190 & 175 & 183.20 \\
\hline \multirow{7}{*}{ Vinyl } & 1 & 197 & 198 & 190 & 192 & 195 & 194.40 \\
\hline & 2 & 187 & 183 & 181 & 185 & 188 & 184.80 \\
\hline & 3 & 177 & 184 & 181 & 179 & 184 & 181.00 \\
\hline & 4 & 185 & 190 & 191 & 187 & 188 & 188.20 \\
\hline & 5 & 184 & 185 & 184 & 186 & 183 & 184.40 \\
\hline & 6 & 180 & 179 & 181 & 178 & 179 & 179.40 \\
\hline & 7 & 177 & 174 & 176 & 176 & 177 & 176.00 \\
\hline \multirow{7}{*}{ Polyurethane } & 1 & 176 & 176 & 179 & 178 & 177 & 177.20 \\
\hline & 2 & 180 & 184 & 183 & 181 & 182 & 182.00 \\
\hline & 3 & 177 & 180 & 176 & 175 & 175 & 176.60 \\
\hline & 4 & 185 & 180 & 183 & 183 & 185 & 183.20 \\
\hline & 5 & 187 & 188 & 187 & 190 & 186 & 187.60 \\
\hline & 6 & 175 & 177 & 177 & 179 & 176 & 176.80 \\
\hline & 7 & 188 & 184 & 185 & 187 & 188 & 186.40 \\
\hline
\end{tabular}

Table 4 Solid by volume for epoxy

\begin{tabular}{|c|c|c|c|c|c|c|c|}
\hline \multicolumn{2}{|c|}{ Spot } & Spot 1 & Spot 2 & Spot 3 & Spot 4 & Spot 5 & Average \\
\hline DFT & Epoxy specimen & 179.857 & 177.286 & 189.714 & 187.714 & 174.714 & 181.857 \\
\hline WFT & Epoxy specimen & 221.571 & 222.143 & 221.429 & 223.571 & 221.857 & 222.114 \\
\hline \multicolumn{2}{|c|}{ Solid by volume } & 0.81173 & 0.79807 & 0.85677 & 0.83962 & 0.78751 & $0.81875^{*}$ \\
\hline
\end{tabular}

Table 5 Solid volume percentage for vinyl

\begin{tabular}{|c|c|c|c|c|c|c|c|}
\hline \multicolumn{2}{|c|}{ Spot } & Spot 1 & Spot 2 & Spot 3 & Spot 4 & Spot 5 & Average \\
\hline DFT & Vinyl specimen & 183.857 & 184.714 & 183.429 & 183.286 & 184.857 & 184.029 \\
\hline WFT & Vinyl specimen & 241.571 & 243.857 & 243 & 242.286 & 240.857 & 242.314 \\
\hline \multicolumn{2}{|c|}{ Solid by volume } & 0.76109 & 0.75747 & 0.75485 & 0.75649 & 0.7675 & $0.75946^{*}$ \\
\hline
\end{tabular}

Table 6 Solid by volume for polyurethane

\begin{tabular}{|c|l|c|c|c|c|c|c|}
\hline \multicolumn{2}{|c|}{ Spot } & Spot 1 & Spot 2 & Spot 3 & Spot 4 & Spot 5 & Average \\
\hline DFT & Polyurethane specimen & 181.143 & 181.286 & 181.429 & 181.857 & 181.286 & 181.40 \\
\hline WFT & Polyurethane specimen & 276.857 & 279 & 275.571 & 276.714 & 278.143 & 277.257 \\
\hline \multicolumn{2}{|c|}{ Solid by volume } & 0.65428 & 0.64977 & 0.65837 & 0.6572 & 0.65177 & $0.65427^{*}$ \\
\hline
\end{tabular}


The predicted dry film thickness (DFT) can be calculated from the wet film thickness (WFT) using the following formula (B. Goldie) [18]:

$$
\text { DFT }=\text { WFT } x \text { Solid by Volume }
$$

* Epoxy coating a solid by volume of 0.819 and a wet film thickness measured at 219.0 $\mu \mathrm{m}$, prediction of $D F T=219.0 \times 0.819=179.361 \mu \mathrm{m}(7.174 \mathrm{mils})$.

* Vinyl coating a solid by volume of 0.759 and a wet film thickness measured at $241.0 \mu \mathrm{m}$, prediction of $D F T=241.0 \times 0.759=182.919 \mu \mathrm{m}(7.317 \mathrm{mils})$.

* Polyurethane coating a solid by volume of 0.654 and a wet film thickness measured at $275.40 \mu \mathrm{m}$, prediction of $D F T=275.40 \times 0.654=180.112 \mu \mathrm{m}(7.204 \mathrm{mils})$.

\subsubsection{Visualisation of tropical weather test}

The test is carried out using a drying rack that conforms to the ASTM standard of G 50 - 10. This drying rack positions of the specimen at an angle of $90^{\circ}$. The position of the $90^{\circ}$ angle specimen aims to mimic the original position of the steel plate on the hull. The direction of the specimens is facing to East and West to follow the position of the sun exposure. Changes in the direction of drying the specimens are carried out manually every $12.00 \mathrm{WIB}$.

\subsubsection{Visualisation of salt spray test}

Salt spray tests were carried out in a salt spray fog chamber following ASTM B 117 standard. The first phase was carried out for 192 hours, then the second phase for 384 hours, and the third phase for 576 hours, so that the total time needed reached 24 days. The final results of the specimens on the salt spray condition performed visually as shown in Figures $11,12,13$ and 14.

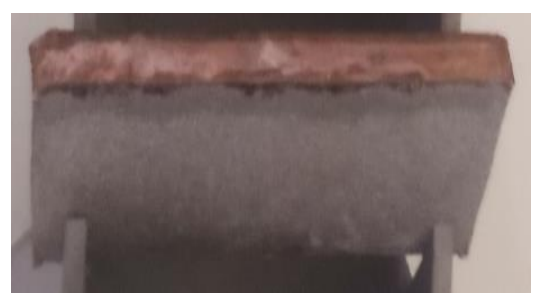

(a) $1^{\text {st }}$ Phase: 192 hours

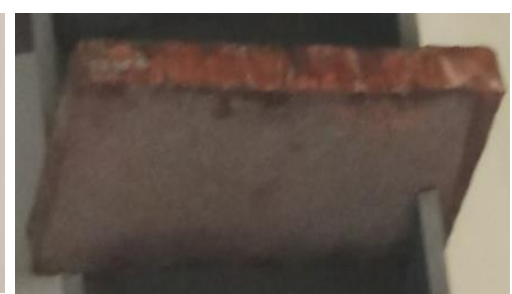

(b) $2^{\text {nd }}$ Phase: 384 hours

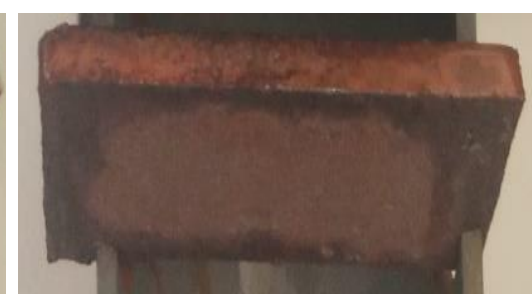

(c) $3^{\text {rd }}$ Phase: 576 hours

Fig. 11 Visualisation of No Coating Specimens

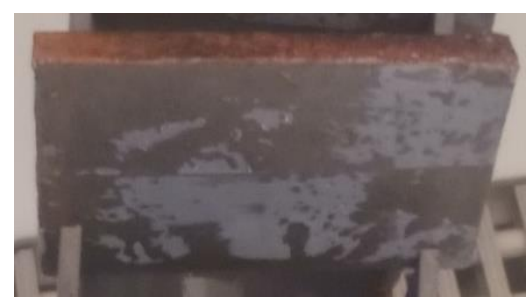

(a) Epoxy

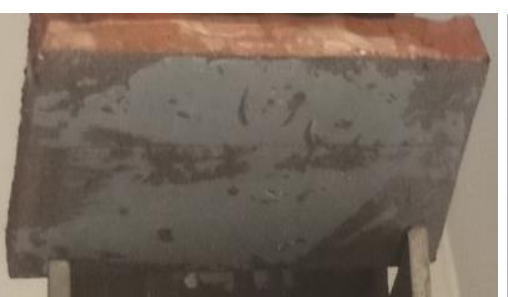

(b) Vinyl

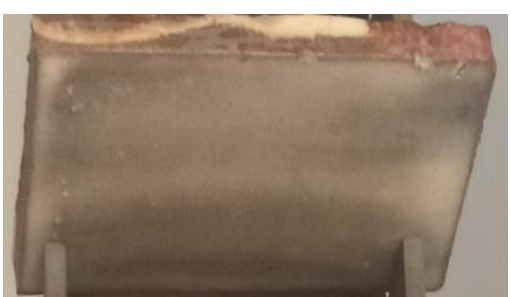

(c) Polyurethane

Fig. 12 Visualisation of Coating Specimens to First Phase: 192 hours

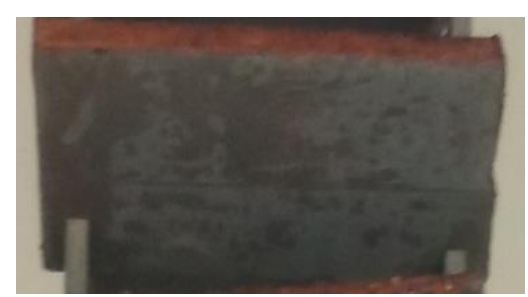

(a) Epoxy

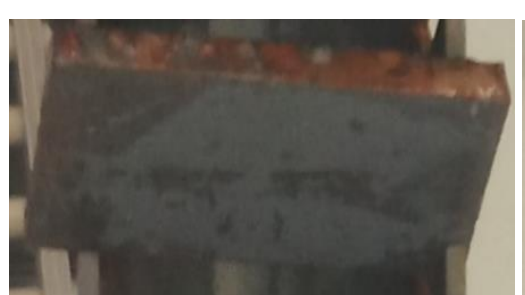

(b) Vinyl

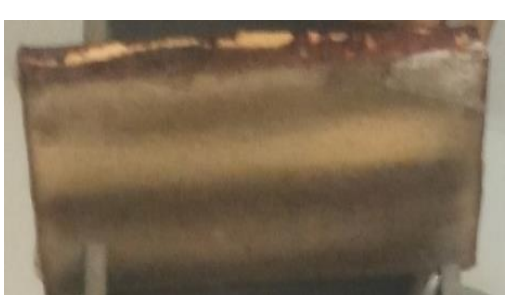

(c) Polyurethane

Fig. 13 Visualisation of Coating Specimens to Second Phase: 384 hours 


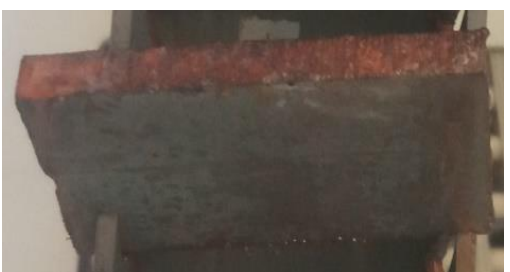

(a) Epoxy

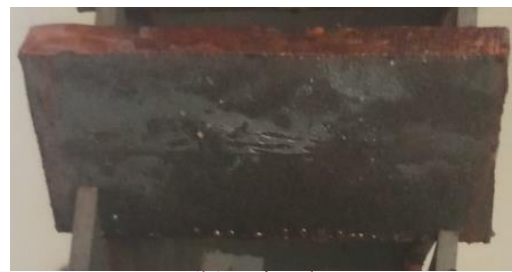

(b) Vinyl

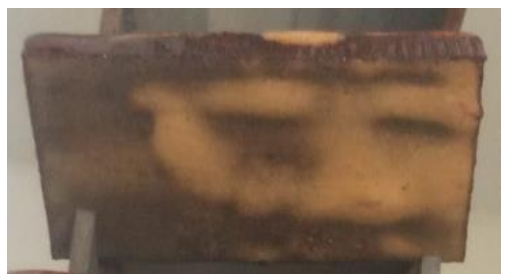

(c) Polyurethane

Fig. 14 Visualisation of Coating Specimens to Third Phase: 576 hours

\subsection{Scanning Electron Microscope}

\subsubsection{SEM: tropical weather test}

SEM study on specimens without coating in tropical weather test performed to obtain the visual information about material corrosion as shown in Figure 15.
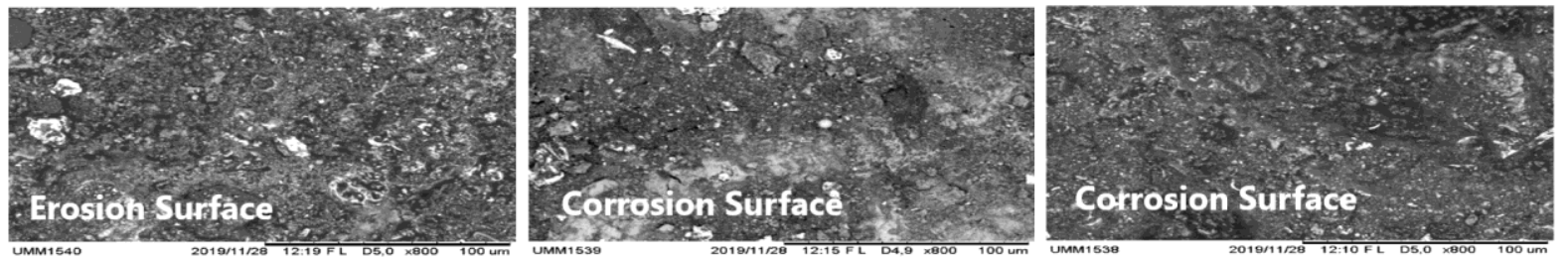

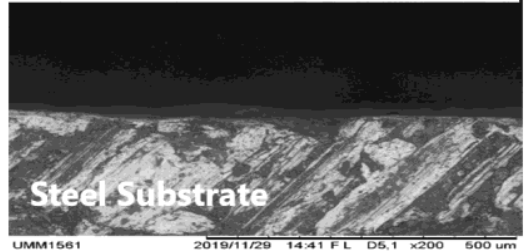

(a) $1^{\text {st }}$ Phase: 192 hours

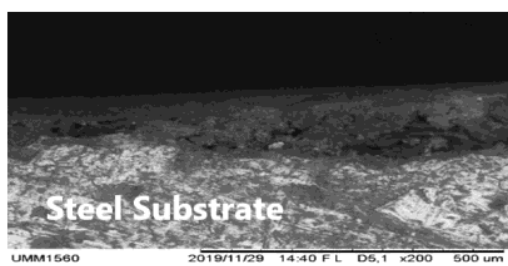

(b) $2^{\text {nd }}$ Phase: 384 hours

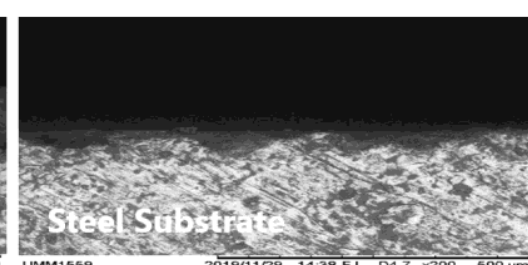

(c) $3^{\text {rd }}$ Phase: 576 hours

Fig. 15 SEM:TWT - No coating (magnification visual of longitudinal x800 and transverse x200)

Based on Figure 15, it showed that the first phase at 192 hours corrosion occurs but has not covered the entire surface of the material so that erosion does not occur significantly. Second phase at 384 hours, corrosion has eroded the surface and changed the surface structure so that the material deformation on the surface part occurs significantly. Third phase at 576 hours, corrosion was increasingly significant and the surface that has been deformed has been separated from the material.

SEM activities on epoxy coating specimens in tropical weather test performed to obtain visual information about coating and material damage as shown in Figure 16.
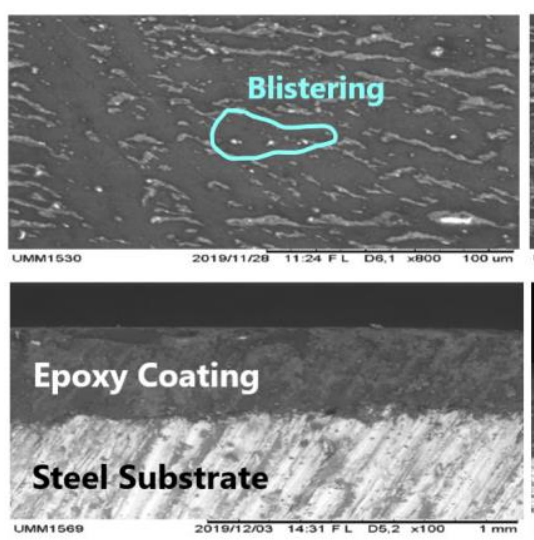

(a) $1^{\text {st }}$ Phase: 192 hours
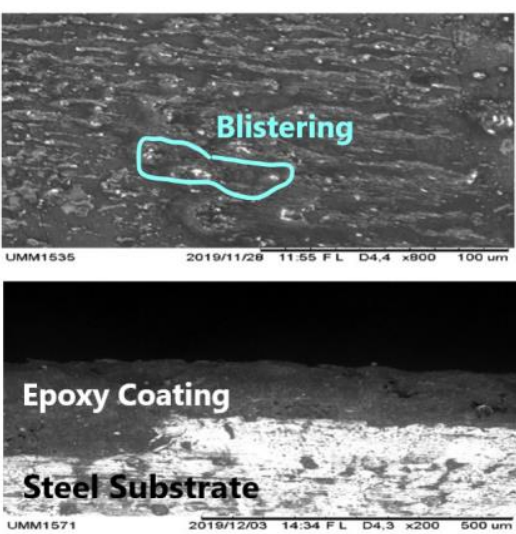

(b) $2^{\text {nd }}$ Phase: 384 hours
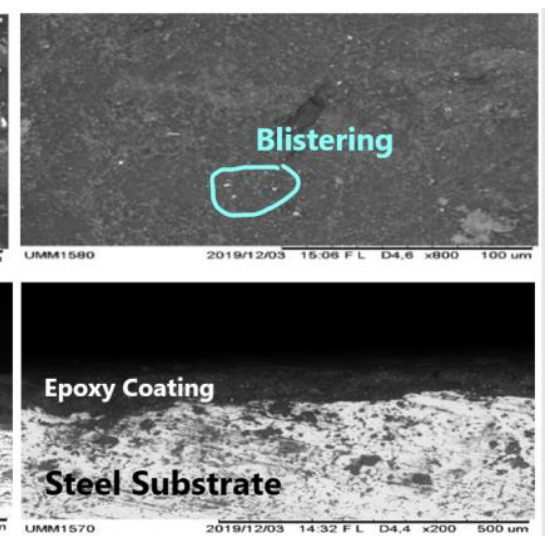

(c) $3^{\text {rd }}$ Phase: 576 hours

Fig. 16 SEM:TWT - Epoxy coating (magnification visual of longitudinal x800 and transverse x200)

Based on Figure 16, it shows that the first phase at 192 hours occurs evenly erosion and fractures on the coating surface. The blister is relatively small when compared to the area of 
the coating in the field of observation. Second phase at 384 hours, the coating was experienced significant erosion and fracture on the surface and coating. Meanwhile, at the base, the coating was still attached to the surface of the material so that the fracture that occurs does not affect the ability of the coating to protect the material from corrosion. Third phase at 576 hours, the epoxy coating remains and covers the surface of the material. This shows that the epoxy coating has a fairly good resistance even after experiencing abrasion and blister potential. The abrasive conditions occur as a result of corrosive environments and sun exposure. According to Da Silva et al. [19] and Linmin Wu et al. [20] showed that the abrasive resistant coatings may be the only feasible option to protect the product surfaces. In situations where, operating temperatures were extremely high, long operating time, and environments not suitable for surface wear.

SEM study on vinyl coating specimens in tropical weather test performed to obtain visual information about coating and material damage as shown in Figure 17.
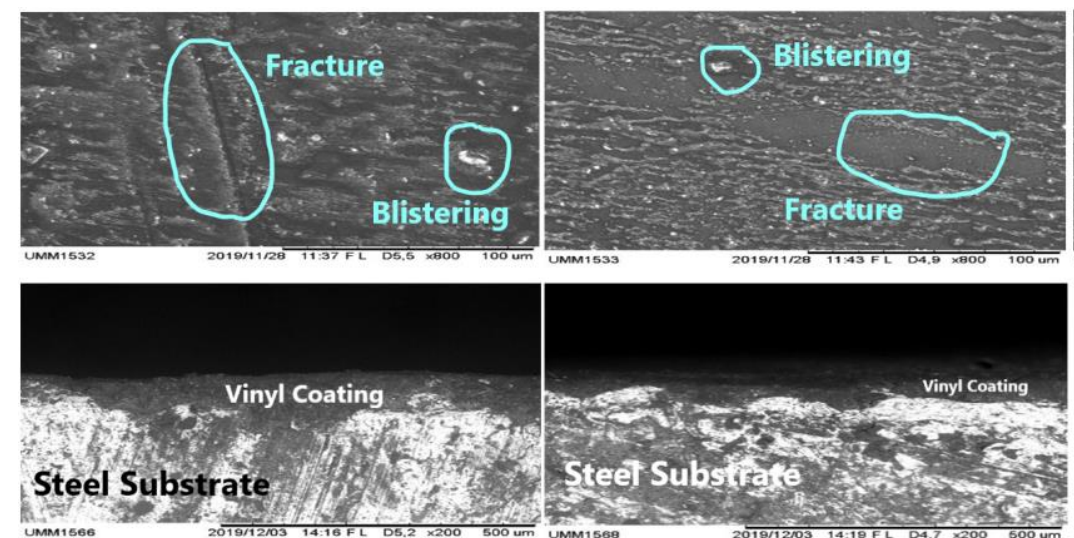

(a) $1^{\text {st }}$ Phase: 192 hours

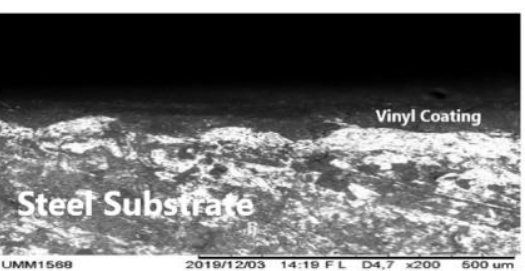

(b) $2^{\text {nd }}$ Phase: 384 hours
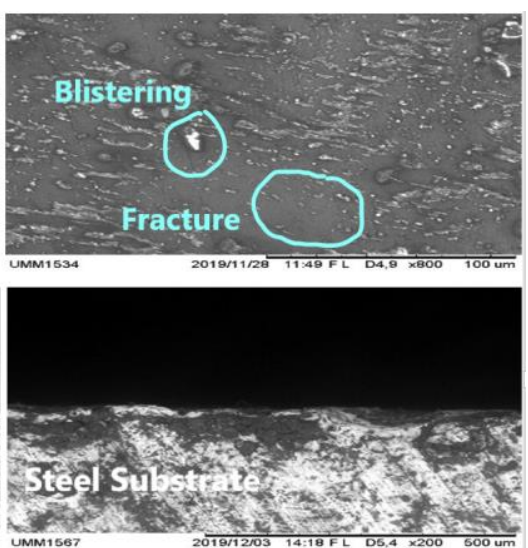

(c) $3^{\text {rd }}$ Phase: 576 hours

Fig. 17 SEM:TWT - Vinyl coating (magnification visual of longitudinal x800 and transverse x200)

Based on Figure 17, it shows that the first phase at 192 hours shown that there was evenly erosion and fracture on the coating surface. The area of the blister was relatively small when compared to the area of the coating in the field of observation. Blisters also occur in coatings that were adjacent to the material but do not interact with the surface of the material. In the second phase at 384 hours, there was uneven erosion, where there was a coating with a thickness higher than other areas. Third phase at 576 hours, there was erosion and the appearance of the material surface. This flatness causes the coating to remain even though it was very thin when compared to the area of the field of observation.

SEM study on polyurethane coating specimens in tropical weather test performed to obtain visual information about coating and material damage as shown in Figure 18.

Based on Figure 18, it shows that the first phase at 192 hours show that there was no blister, but there were fractures on the surface, inside, and the base of the coating, as well as some parts of the coating that do not stick to the surface of the material. In the cross-section, a relatively large, round cavity was formed from air trapped during the curing process. Second phase at 384 hours, there were uneven erosion. There was a coating with a thickness higher than other areas. In thicker coatings there are fractures that interact with the surface of the material. Meanwhile, cross-sectional observations show that there were deeper holes and nonuniformity in the coating thickness. Third phase at 576 hours, it appears that the basic part of the coating was attached to the surface of the material, but there were fractures throughout the coating. On cross-sectional observation, the holes in the coating became smaller and the area around the holes was covered by a coating with a finer texture like sand. 

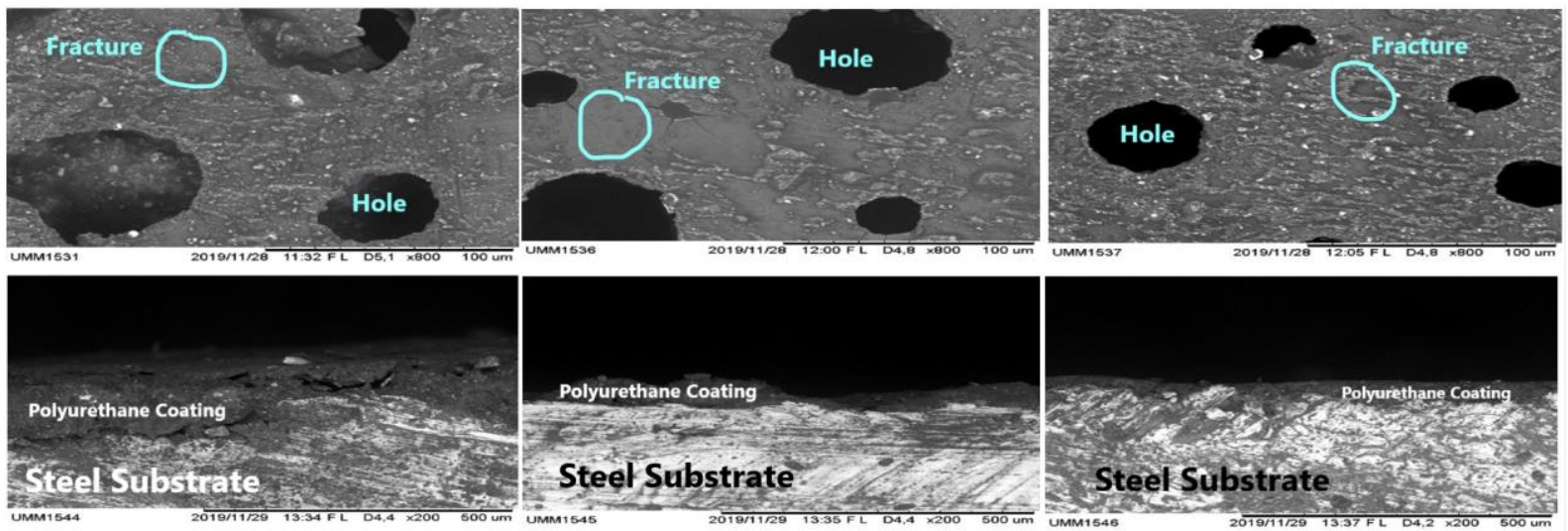

(a) $1^{\text {st }}$ Phase: 192 hours

(b) $2^{\text {nd }}$ Phase: 384 hours

(c) $3^{\text {rd }}$ Phase: 576 hours

Fig. 18 SEM:TWT - Polyurethane coating (magnification visual of longitudinal x 800 and transverse x200)

\subsubsection{SEM: salt spray test}

SEM study on specimens without coating in salt spray test performed to obtain visual information about bare material resistance as shown in Figure 19.
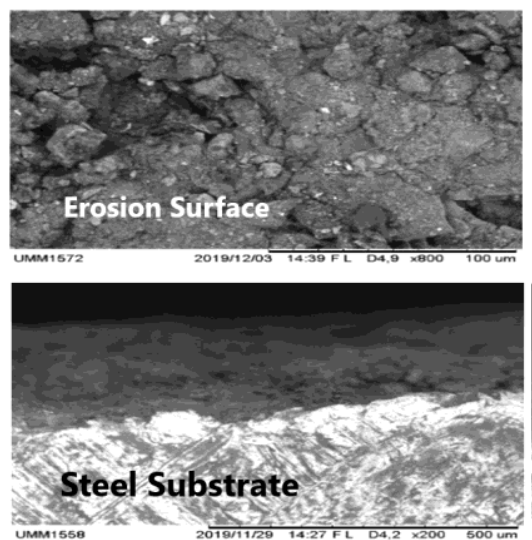

(a) $1^{\text {st }}$ Phase: 192 hours
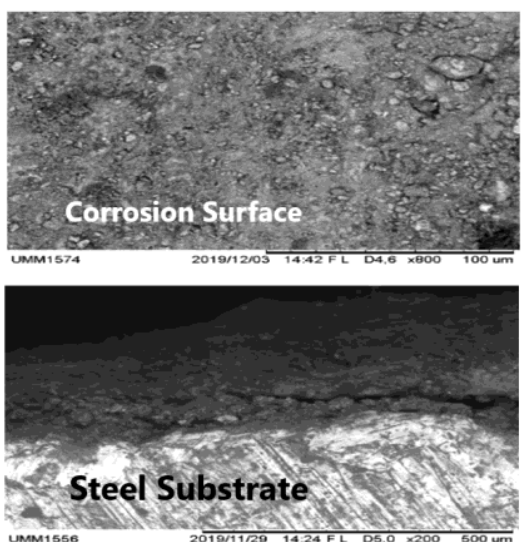

(b) $2^{\text {nd }}$ Phase: 384 hours
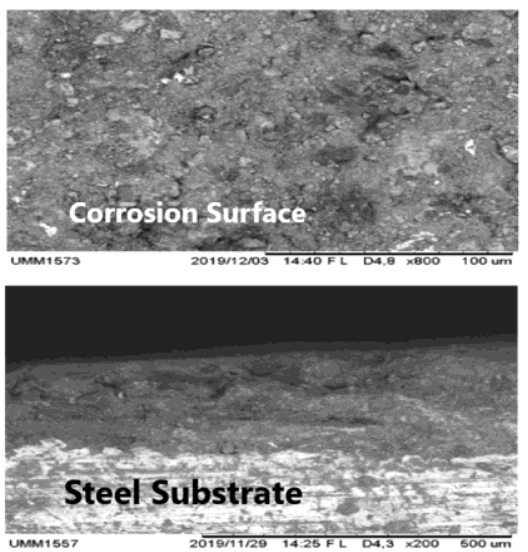

(c) $3^{\text {rd }}$ Phase: 576 hours

Fig. 19 SEM:SST - No coating (magnification visual of longitudinal x 800 and transverse $\mathrm{x} 200$ )

Based on Figure 19, it shows that the first phase at 192 hours begins to occur at a minimum, but it has not been significantly proven that there were still intact blasting particles. Second phase at 384 hours, there has been erosion of the surface and changes in the structure of the hollow steel surface. Scraping occurs at the edge of the specimen and was uneven. Third phase at 576 hours, there was a significant change in the surface structure, where the specimen was evenly eroded and there was no residual blasting.

SEM study on epoxy coating specimens in salt spray test performed to obtain visual information about coating and material damage as shown in Figure 20. 

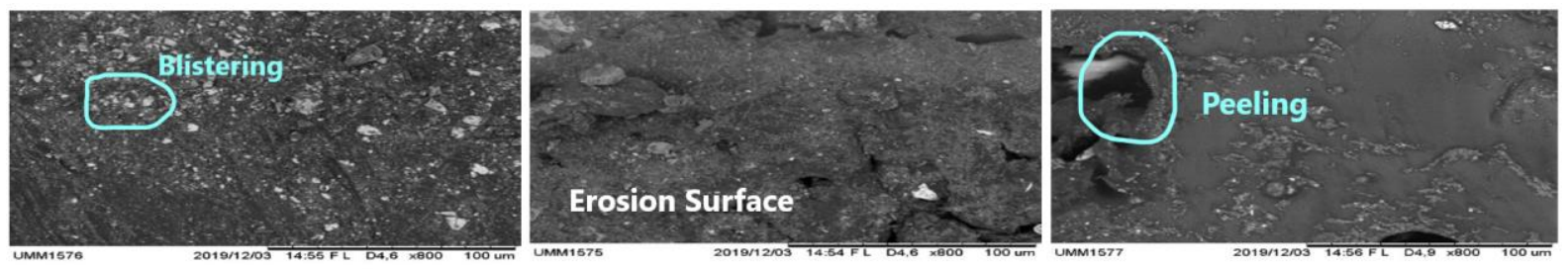

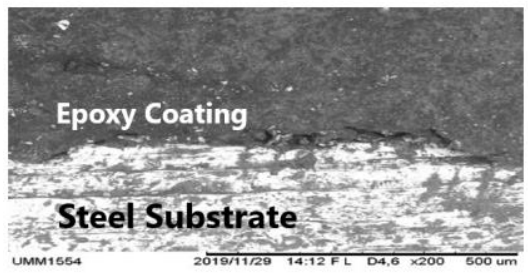

(a) $1^{\text {st }}$ Phase: 192 hours

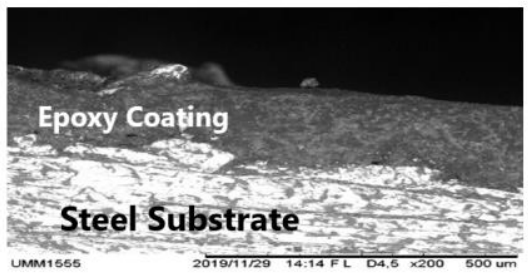

(b) $2^{\text {nd }}$ Phase: 384 hours

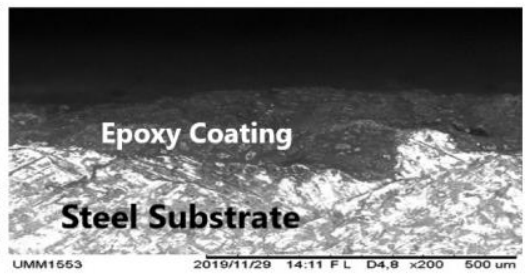

(c) $3^{\text {rd }}$ Phase: 576 hours

Fig. 20 SEM:SST - Epoxy coating (magnification visual of longitudinal x800 and transverse x200)

Based on Figure 20, it shows that the first phase at 192 hours begins to appear blisters occur in epoxy coatings, where blisters mainly occur in coatings that interact with the material. On the other hand, epoxy has fairly good adhesive properties and was shown by bonding the epoxy layer to the steel surface. Second phase at 384 hours, there was erosion on the surface of the layer, where the blister was found to be more spread out in the interacting part but still close to the steel surface. Third phase at 576 hours, significant erosion occurred. There were some areas where peeling has occurred and the coating structure becomes hollow, but there were some parts that were still protected by the epoxy layer.

SEM study on vinyl coating specimens in salt spray test performed to obtain visual information about coating and material damage as show in Figure 21.
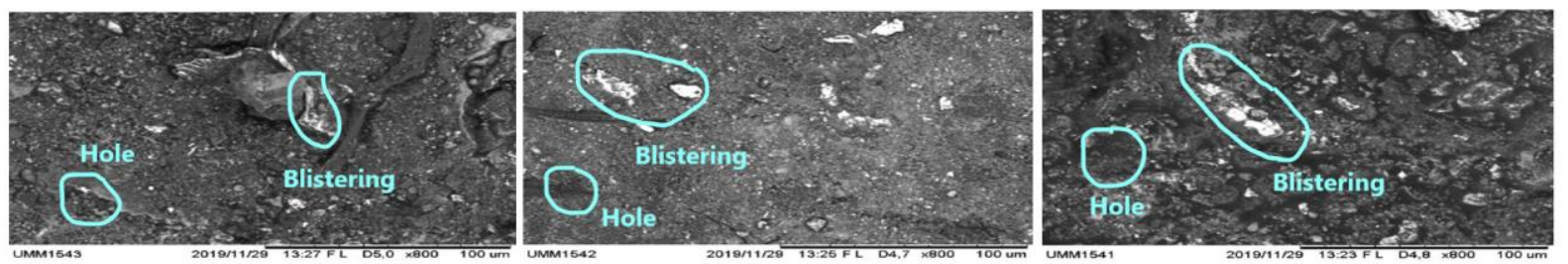

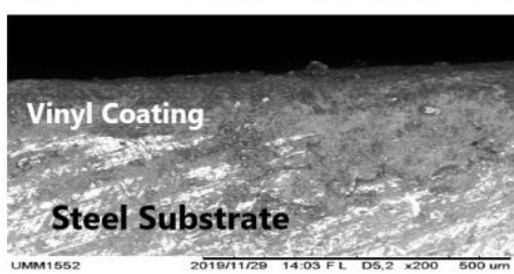

(a) $1^{\text {st }}$ Phase: 192 hours

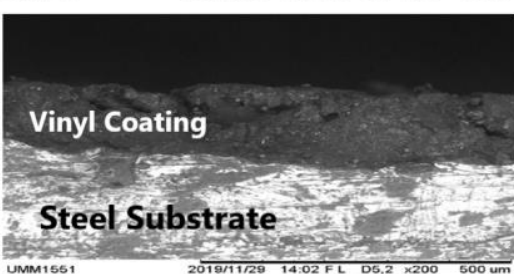

(b) $2^{\text {nd }}$ Phase: 384 hours

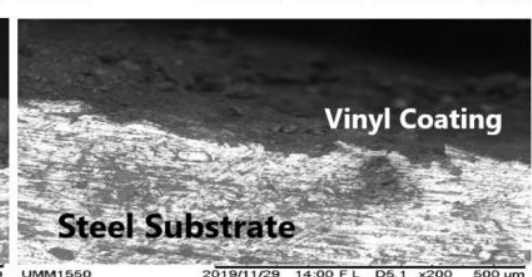

(c) $3^{\text {rd }}$ Phase: 576 hours

Fig. 21 SEM:SST - Vinyl coating (magnification visual of longitudinal x800 and transverse x200)

Based on Figure 21, it shows that the first phase at 192 hours shown that the specimens with vinyl resin coating experienced blisters in the layers adjacent to the material, but did not interact with the surface of the material. Meanwhile, vinyl coatings have good adhesive properties. Vinyl coating can get into the crevices of the material surface. Second phase at 384 hours, the blister changes the structure of the coating. In the coating there were fractures caused by small holes on the surface of the coating. These small holes cause salt water to enter and erode the inside of the layer. Third phase at 576 hours, the appearance of the material surface in several areas were cause in a very significant change in the coating structure. There were several coatings that get into the crevices of the surface of the material that have not been eroded and protect the surface of the material.

SEM study on polyurethane coating specimens in salt spray test performed to obtain visual information about coating and material damage as shown in Figure 22. 

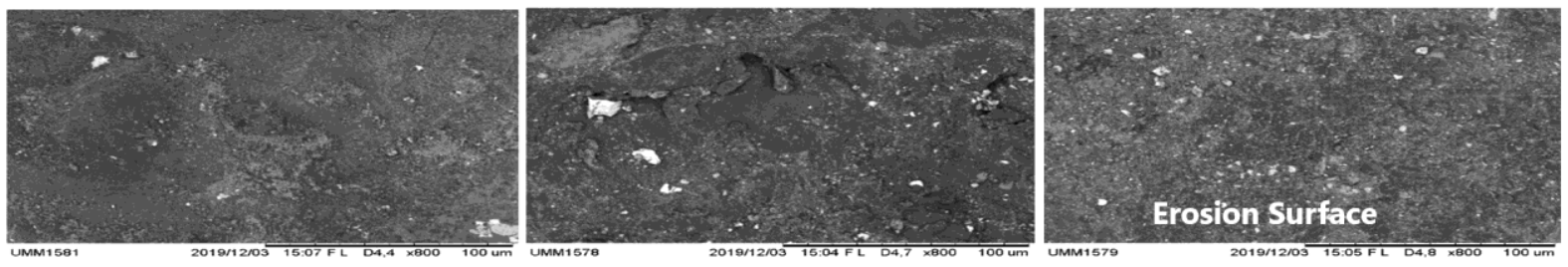

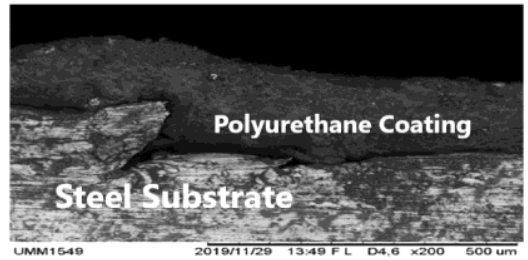

(a) $1^{\text {st }}$ Phase: 192 hours

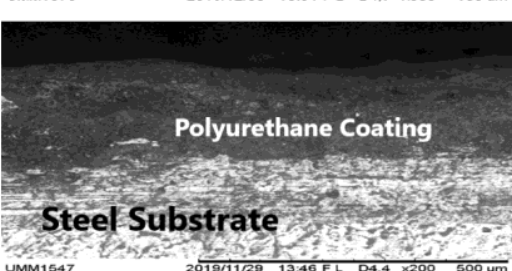

(b) $2^{\text {nd }}$ Phase: 384 hours

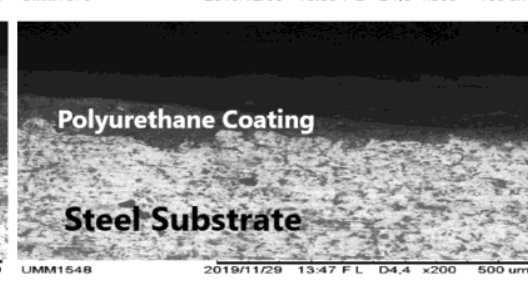

(c) $3^{\text {rd }}$ Phase: 576 hours

Fig. 22 SEM:SST - Polyurethane coating (magnification visual of longitudinal x 800 and transverse x200)

Based on Figure 22, it shows that the first phase at 192 hours show that the polyurethane coating does not appear to blend with the surface of the material but there was no blister. Second phase at 384 hours, no blister and polyurethane coating can blend with the surface of the material. Third phase at 576 hours, the polyurethane coating remains resistant to blisters and can blend with the surface of the material, but on the other hand there was significant erosion of the coating surface.

\subsection{Adhesive Test}

\subsubsection{AT: tropical weather condition}

Specimens in tropical weather test for 576 hours show that the adhesion value $0 \%$ of constant, cohesion 30 to $80 \%$, glue 20 to $70 \%$, and adhesive 3.95 to $11.87 \mathrm{MPa}$ as shown in Table 7.

Table 7 Adhesive test: tropical weather condition

\begin{tabular}{|c|c|c|c|c|c|c|c|c|c|c|c|c|c|}
\hline \multirow{2}{*}{$\begin{array}{c}\text { Time } \\
\text { (hours) }\end{array}$} & \multirow{2}{*}{ Point } & \multicolumn{3}{|c|}{ Adhesion (\%) } & \multicolumn{3}{|c|}{ Cohesion (\%) } & \multicolumn{3}{|c|}{ Glue (\%) } & \multicolumn{3}{|c|}{ Adhesive (MPa) } \\
\hline & & $\mathbf{E}$ & $\mathbf{V}$ & $\mathbf{P}$ & $\mathbf{E}$ & $\mathbf{V}$ & $\mathbf{P}$ & $\mathbf{E}$ & $\mathbf{V}$ & $\mathbf{P}$ & $\mathbf{E}$ & $\mathbf{V}$ & $\mathbf{P}$ \\
\hline \multirow{2}{*}{0} & $\mathrm{P}-1$ & 0 & 10 & 15 & 0 & 25 & 25 & 100 & 65 & 60 & 17.18 & 15.65 & 15.65 \\
\hline & $\mathrm{P}-2$ & 10 & 0 & 0 & 0 & 0 & 0 & 90 & 100 & 100 & 21.78 & 20.66 & 20.66 \\
\hline \multirow{2}{*}{192} & P-1 & 0 & 0 & 0 & 30 & 80 & 0 & 70 & 20 & 100 & 15.27 & 4.79 & 9.59 \\
\hline & $\mathrm{P}-2$ & 0 & 0 & 0 & 50 & 25 & 20 & 50 & 75 & 80 & 14.58 & 3.8 & 8.77 \\
\hline \multirow{2}{*}{384} & $\mathrm{P}-1$ & 0 & 0 & 0 & 30 & 40 & 90 & 70 & 60 & 10 & 9.66 & 9.65 & 9.38 \\
\hline & $\mathrm{P}-2$ & 0 & 0 & 0 & 40 & 30 & 40 & 60 & 70 & 60 & 14.91 & 8.74 & 12.32 \\
\hline \multirow{2}{*}{576} & $\mathrm{P}-1$ & 0 & 0 & 0 & 35 & 30 & 75 & 65 & 70 & 25 & 5.1 & 5.71 & 11.87 \\
\hline & $\mathrm{P}-2$ & 0 & 0 & 0 & 45 & 45 & 80 & 55 & 55 & 20 & 5.75 & 3.95 & 9.25 \\
\hline
\end{tabular}

Note: $\mathrm{E}=$ epoxy; $\mathrm{V}=$ vinyl; $\mathrm{P}=$ polyurethane

Trend lines of polynomial function on the adhesion that occurs in epoxy, vinyl, and polyurethane coatings in tropical weather conditions as shown in Figure 23. 


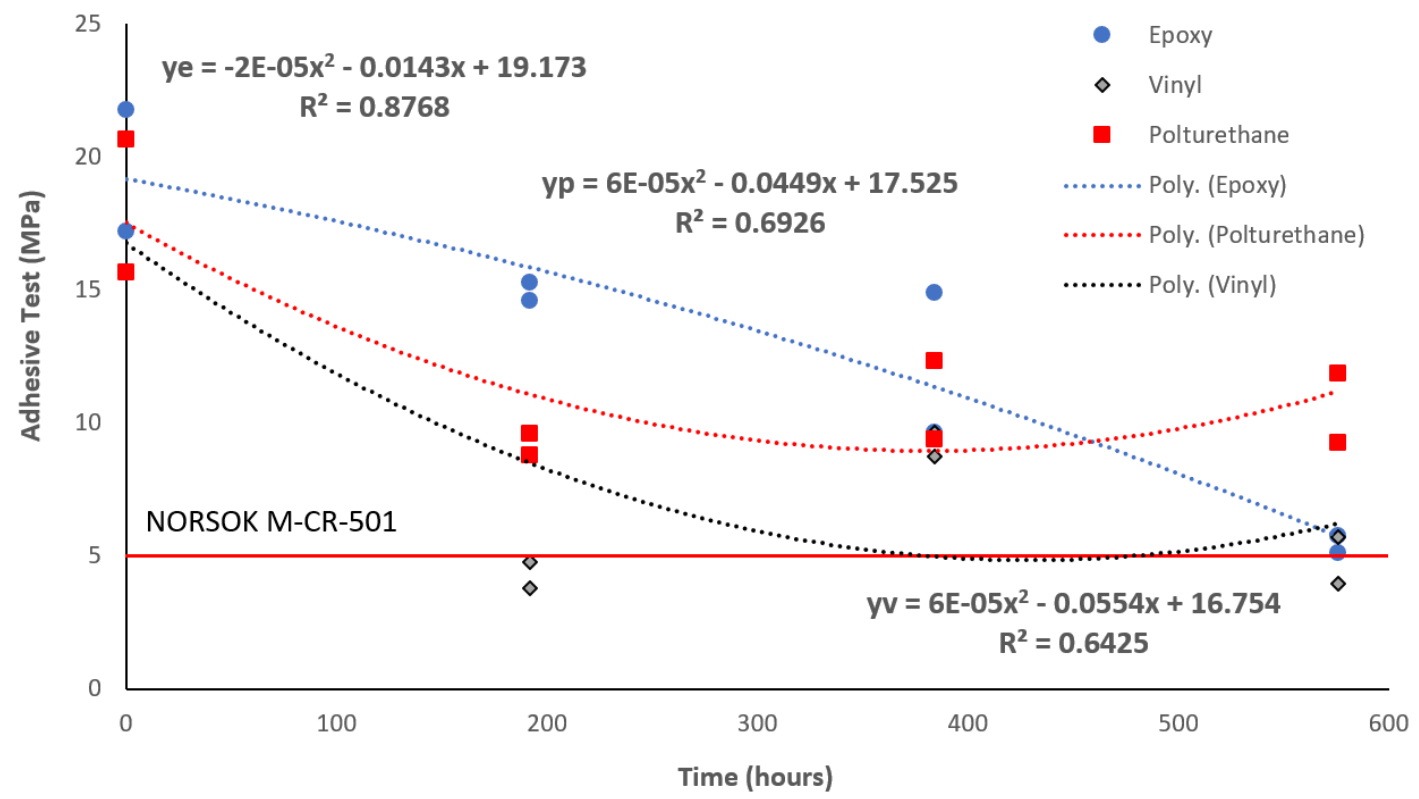

Fig. 23 Trend lines of Adhesive Test: TWC - Epoxy/Vinyl/Polyurethane Coating

Figure 23 showed that the trendlines of epoxy, vinyl, and polyurethane coating have a second polynomial order. Meanwhile, the horizontal line of NORSOK M-CR-501 was the limit of adhesion that was allowed at least $5 \mathrm{MPa}$. Taking into account the three polynomial trendlines and horizontal lines of NORSOK M-CR-501 shows that polyurethane coating in tropical weather conditions has the best adhesion power than epoxy and vinyl coating.

\subsubsection{AT: salt spray condition}

Specimens in salt spray test for 576 hours show that adhesion value 0 to $40 \%$, cohesion 0 to $45 \%$, glue 60 to $95 \%$, and adhesive 2.64 to $4.31 \mathrm{MPa}$ as shown in Table 8 .

Table 8 Adhesive test: salt spray test

\begin{tabular}{|c|c|c|c|c|c|c|c|c|c|c|c|c|c|}
\hline \multirow{2}{*}{$\begin{array}{c}\text { Time } \\
\text { (hours) }\end{array}$} & \multirow{2}{*}{ Point } & \multicolumn{3}{|c|}{ Adhesion (\%) } & \multicolumn{3}{|c|}{ Cohesion (\%) } & \multicolumn{3}{|c|}{ Glue (\%) } & \multicolumn{3}{|c|}{ Adhesive (MPa) } \\
\hline & & $\mathbf{E}$ & $\mathbf{V}$ & $\mathbf{P}$ & $\mathbf{E}$ & $\mathbf{V}$ & $\mathbf{P}$ & $\mathbf{E}$ & $\mathbf{V}$ & $\mathbf{P}$ & $\mathbf{E}$ & $\mathbf{V}$ & $\bar{P}$ \\
\hline & P-1 & 0 & 25 & & & 25 & 25 & 00 & 65 & 60 & 17.18 & 15.65 & 15.6 \\
\hline & & 10 & 0 & & & & & 0 & 100 & 100 & 21.78 & 20.66 & 20.66 \\
\hline & & 0 & 25 & & 75 & 80 & 0 & 5 & 75 & 5 & 3.91 & 3.6 & 8.77 \\
\hline & $\mathrm{P}-2$ & 0 & 4 & & 65 & 25 & & 35 & 60 & 0 & 3.12 & 3.00 & 9.51 \\
\hline \multirow{2}{*}{384} & & 0 & 4 & & & 40 & & 00 & 5 & 90 & 4.1 & $3 .($ & 5.71 \\
\hline & $\mathrm{P}-\mathrm{T}$ & 0 & 6 & 10 & 0 & 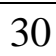 & 10 & 100 & 35 & 80 & 2.64 & 4.95 & 9.20 \\
\hline \multirow{2}{*}{576} & & 0 & 20 & 1 & 25 & 30 & 0 & 75 & 80 & 85 & 4.10 & 3.51 & 3.51 \\
\hline & $\mathrm{P}-1$ & 0 & 40 & 5 & 35 & 45 & 0 & 65 & 60 & 95 & 4.31 & 2.64 & 2.64 \\
\hline
\end{tabular}

Note: $\mathrm{E}=$ epoxy; $\mathrm{V}=$ vinyl; $\mathrm{P}=$ polyurethane

Trend lines of polynomial function on the adhesion that occurs in epoxy, vinyl, polyurethane coatings in salt spray condition as shown in Figure 24. 


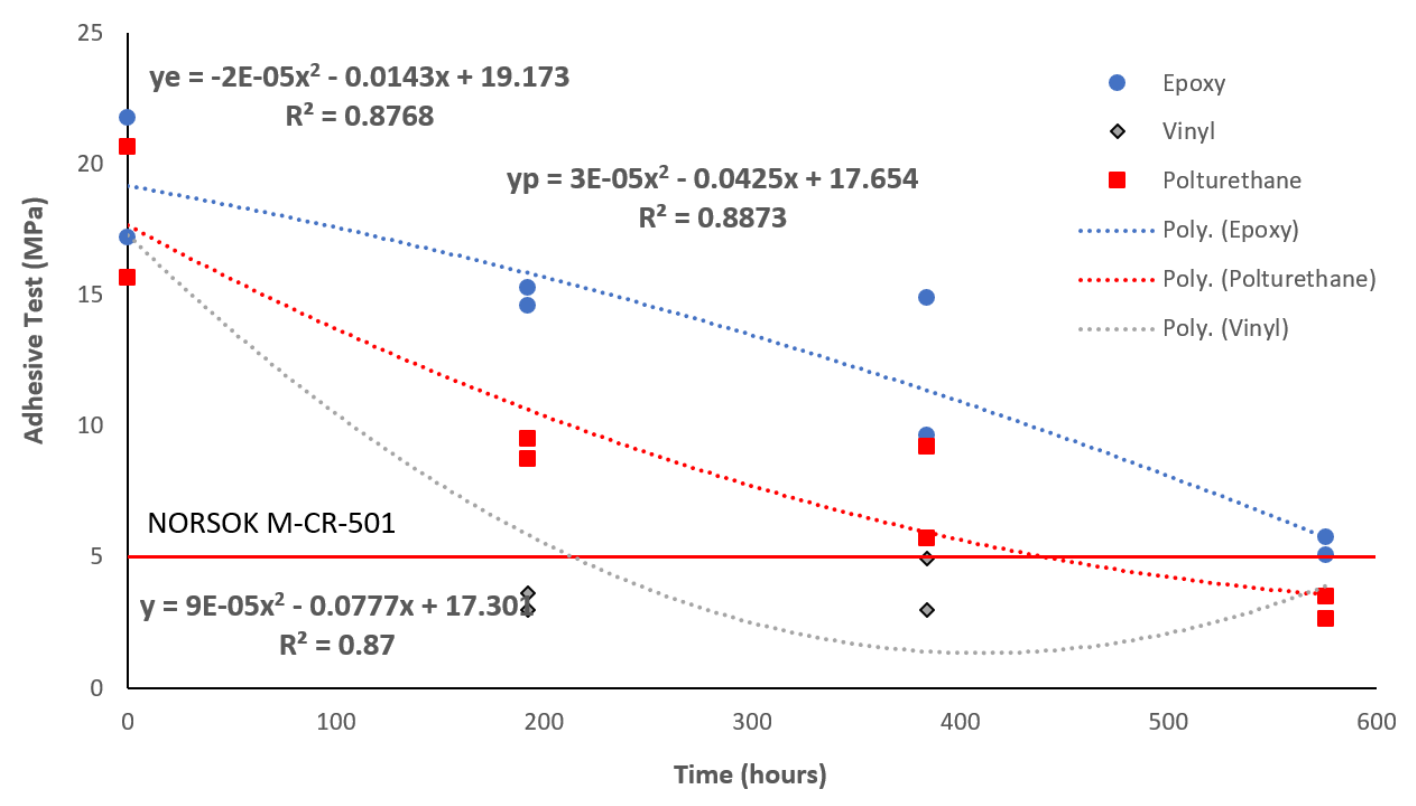

Fig. 24 Trend lines of Adhesive Test: SSC - Epoxy/Vinyl/Polyurethane Coating

Figure 24 showed that the trendlines of epoxy, vinyl, and polyurethane coating have a second polynomial order. Meanwhile, the horizontal line of NORSOK M-CR-501 was the limit of the permissible adhesive power of at least $5 \mathrm{MPa}$. Taking into account the three polynomial trendlines and horizontal lines of NORSOK M-CR-501 shows that the epoxy coating on salt spray has the best adhesion power than vinyl and polyurethane coatings.

\section{Conclusions}

Tropical weather conditions as the result of SEM show that the polyurethane coating has the best coating compared to epoxy and vinyl layers. After the 576 hour phase, there was no indication of loss occurring uniformly in the observation area.

Salt spray conditions from SEM show that epoxy coatings have the best coating than polyurethane and vinyl coatings. After the 576 hours phase show that an indication of a denser coating structure and less blistering in the observed area.

Tropical weather conditions show that the three trend lines of epoxy, vinyl, and polyurethane coating have a second order polynomial form and polyurethane coatings have the best adhesion power than epoxy and vinyl coatings. The average adhesion ability of the polyurethane coating at 576 hours was $10.56 \mathrm{MPa}$.

The salt spray condition shows that the three trend lines of epoxy, vinyl, and polyurethane coating have a second order polynomial form and the epoxy coating has the best adhesion than vinyl and polyurethane coatings. The average adhesive power of the epoxy coating in 576 hours was 4,205 MPa.

The protection implication of ship steel uses an organic coating: Epoxy, Vinyl, and Polyurethane as Anti-Corrosive (AC) were divided into three main groups: Oxidizing (conventional AC coatings), One-component (physically dry), and Two-components (chemically dry).

Oxidizing. Representatives: oil coatings, alkyd coatings, urethane oils, epoxy esters, phenolic coatings. Applications: decks, superstructures, engine rooms, belt line.

One-component. Vinyl to applications: decks. Vinyl-tar (a combination of conventional and complex coatings) to applications: boot topping, wetted area primer, ballast and cargo tanks. 
Two-components. Polyurethane coating to application: superstructure. Epoxy coating to applications: hull plating, tanks. Tar-epoxy coatings to applications: boot topping, wetted area, ballast and cargo tanks.

The epoxy coating was customarily applied as a shop primer (using one layer) which functions as temporary protection before the ship construction process at the fabrication to assembly stage. If the epoxy or polyurethane coating was applied as anti-corrosive (after assembly stage) should using two layers.

\section{Acknowledgements}

Authors would like to thank you to the PPUPIK - Kemaritiman: National Competitive Grant Program from Kemendikbud - Indonesia, the FTIK Laboratory - University of Hang Tuah, the Laboratory of Muhammadiyah Malang University, the Laboratory of Chemical and Material from Indonesian Navy, the Workshop from Safinah Laras Persada Company, and the Laboratory of Cipta Agung Company.

\section{REFERENCES}

[1] P. R. Roberge, Corrosion Engineering: Principles and Practice, New York: McGraw-Hill Companies, 2008.

[2] S.B. Lyon, R. Bingham and D.J. Mills, "Advances in Corrosion Protection by Organic Coatings: What We Know and What We Would Like to Know", Progress in Organics Coatings, vol. 102, pp. 2-7, 2017. https://doi.org/10.1016/j.porgcoat.2016.04.030

[3] E.M. Kinsella and J.E.O. Mayne, "Ionic Conduction in Polymer Films I. Influence of Electrolyte on Resistance", British Polymer Journal, vol. 1, issue 4, pp. 173-176, 1969. https://doi.org/10.1002/pi.4980010405

[4] C. D. Claver, Applied Polymer Science: 21st Century, Oxford UK: Elsevier, 2000.

[5] O. C. Zaske and S. H. Goodman, Handbook Thermoset Plastics, Second Edition, New Jersey: Noyes Publication, 1998.

[6] H. Dodiouk and S. H. Goodman, Handbook of Thermoset Plastics, Third Edition, Oxford: Elsevier (William Andrew Publishing), 2014.

[7] Yong Li, Jin Fu, Wei Chen, Wenjing Yang, Xueming Li, Yanjun Yin, and Qihui Wang "Corrosive Behavior Study of Q235 Steel Coated with Epoxy Composites in Substation Environment", Advanced in Engineering Research, vol. 113, pp. 561-566, IFMCA 2016.

[8] R. Vera, Cruz, E., Bagnara, M., Araya, R., Henriquez, R., Diaz-Gomes, A., and Rojas, "Evaluation of Anticorrosive Coating on Carbon Steel in Marine Environments: Accelerated Corrosion Test and Field Exposure", International Journal of Electrochemical Science, pp. 898-914, 2018. https://doi.org/10.20964/2018.01.66

[9] A. M. Berendsen, Maritime Painting Manual, Rotterdam: Springer, 1989. https://doi.org/10.1007/978-94$\underline{017-2186-8}$

[10] K. Akhtar, S. A. Khan, S. B. Khan, and A. M. Asiri, Scanning Electron Microscopy: Principle and Applications in Nanomaterials Characterization, S. K. Sharma (ed.), Chapter 4: Handbook of Materials Characterization, Springer International Publishing AG, part of Springer Nature 2018. https://doi.org/10.1007/978-3-319-92955-2_4

[11] Mike Yi, A Complete Guide to Scatter Plots, Chartio, 2019.

[12] M. Friendly and D. Denis, "The Early Origins and Development of the Scatterplot", Journal of the History of the Behavioral Sciences, vol. 41, no. 2, pp. 103-130, 2005. https://doi.org/10.1002/jhbs.20078

[13] D. A. Keim, M. C. Hao, U. Dayal, H. Janetzko and P. Bak, "Generalized Scatter Plots", Information Visualization, vol. 9, no. 4, pp. 301-311, 2010. https://doi.org/10.1057/ivs.2009.34

[14] W. Selzer, Overall Approach to Technical Analysis, Wealth Skills: Understanding Investment Cycles, 2013.

[15] M. David, How to Design Dashboard, Chartio, 2020.

[16] J. W. Gooch, Coefficient of Determination, in Encyclopedic Dictionary of Polymers, 2011. https://doi.org/10.1007/978-1-4419-6247-8_15182 
[17] C. Trijatmiko, H. Pratikno, and A. Purniawan, "Analisa Pengaruh Material Abrasif Pada Blasting Terhadap Kekuatan Lekat Cat dan Ketahanan Korosi di Lingkungan Air Laut”, Jurnal Teknik ITS, vol. 5, no. 2, pp. 231-236, 2016. https://doi.org/10.12962/j23373539.v5i2.18090

[18] B. Goldie, Apllicator Training Bulletin: Computing Film Thickness and Coverage, PCE European, Technology Publishing Company, 2000.

[19] W.M.C. Da Silva, H.L. de Mello, H.L., "Transitions in Abrasive Wear Mechanisms: Effect of the Superimposition of Interactions", Wear, vol. 271, pp. 977-986, 2011. https://doi.org/10.1016/j.wear.2011.04.010

[20] Linmin Wu, Xingye Guo, \& Jing Zhang, “Abrasive Resistant Coatings - A Review”, Lubricants, vol. 2 , pp. 66-89, 2014. https://doi.org/10.3390/lubricants2020066

Submitted: $\quad 25.02 .2021$.

Accepted: $\quad 26.05 .2021$
Bagiyo Suwasono*, bagiyo.suwasono@hangtuah.ac.id, Associate Professor, Department of Engineering and Marine Science, University of Hang Tuah, Surabaya - Indonesia.

I Kadek Agus Sudama Putra, agusk909085@gmail.com, Department of Engineering and Marine Science, University of Hang Tuah, Surabaya - Indonesia.

Tri Agung Kristiyono, arek.kapa197@gmail.com, PhD. Student, Departement of Environmental, Brawijaya University, Malang Indonesia .

Ali Azhar, alif_7176@yahoo.co.id, PhD. Student, Departement of Environmental, Brawijaya University, Malang - Indonesia 